\title{
AVALIAÇÃO DA QUALIDADE DO SOLO POR MEIO DE TEORES DE MATÉRIA ORGÂNICA E ATIVIDADE BIOLÓGICA
}

\section{Wedson Aleff Oliveira da Silva'; David Marx Antunes de Melo²; Gabriel Torres Rodrigues ${ }^{3}$; Gerson João da Silva ${ }^{4}$; Paulo César Carneiro Barreto5; Alexandre Eduardo de Araújo ${ }^{6}$}

\author{
${ }^{1}$ Mestrando/Pós-graduação em Ciências Agrárias, (UEPB), Campina Grande, Paraíba, ${ }^{2}$ Doutorando/ \\ Programa de Pós-Graduação em Agronomia, UFPB, Areia, Paraíba, ${ }^{3}$ Mestrando/Programa de \\ Pós-Graduação em Agronomia, UFPB, Areia, Paraíba, ${ }^{4}$ Bacharelando em Agroecologia, UFPB, \\ Bananeiras, Paraíba, ${ }^{5}$ Bacharelando em Agroecologia, UFPB, Bananeiras, Paraíba, 6 Doutor Eng. \\ Agrícola, Departamento de Agricultura, UFPB, Bananeiras, Paraíba.
}

DOI: 10.47094/ICONNECA.2021/24

\begin{abstract}
RESUMO
Os teores de matéria orgânica e a atividade biológica são indicadores determinantes para avaliação da qualidade de um solo, onde diferentes técnicas de manejo do solo refletem diretamente na condição de sustentabilidade de um agroecossistema. Desse modo, o objetivo foi avaliar indicadores de qualidade física do solo de dois subsistemas agrícolas experimentais com diferentes usos e sistemas de manejo. Logo, testamos a hipótese de que os sistemas agroflorestais possuem solos com melhor qualidade do que sistemas de base convencional. Avaliou-se os teores de matéria orgânica e atividade biológica como indicador da qualidade do solo de três diferentes sistemas de plantio e da mata nativa em um agroecossistema familiar. Como resultados, observou-se para os dois indicadores, maiores níveis no sistema de produção de hortaliças e na mata nativa. Os demais subsistemas avaliados, apesar de apresentarem menores valores quanto aos níveis de matéria orgânica e atividade biológica, também possuem boa qualidade do solo, sendo uma fundamental condição do fortalecimento da agricultura familiar, segurança alimentar e nutricional.
\end{abstract}

PALAVRAS-CHAVES: Indicadores. Saúde do solo. Subsistemas.

ÁREA TEMÁTICA: Gestão Ambiental.

\section{INTRODUÇÃO}

Um solo de boa qualidade é aquele que possui diversidade biológica, capaz de sustentar atividade de produção com qualidade ambiental (DORAN et al., 1996; BALOTA, 2018). No que diz respeito à fertilidade, analisar os atributos físicos, químicos e biológicos de forma isolada se torna inviável tendo em vista a complexidade da biocenose e a dinâmica dos processos que nela ocorrem (PRIMAVESI; PRIMAVESI, 2018). 
Diante disso, a matéria orgânica do solo (MOS) é o parâmetro químico do solo que melhor se correlaciona com os demais parâmetros indicadores da qualidade do solo, seja do ponto de vista físico, químico ou biológico (MIELNICZUK, 2008).

Segundo Machado e Machado Filho (2017), é possível avaliar a qualidade do solo por meio da MOS e atividade biológica, pois, as mesmas alteram os diferentes sistemas de manejo do solo, podendo assim, refletir sua condição de sustentabilidade, porém, quando submetidas a manejo inadequado, sofrem alterações em sua atividade.

Neste sentido, é de grande importância a utilização de métodos acessíveis voltados para a análise da qualidade do solo, tendo em vista a importância desse indicador para o manejo agrícola e a sustentabilidade dos agroecossistemas (CARDOSO; FÁVERO, 2018).

Dessa forma, objetivou-se com essa pesquisa avaliar teores de matéria orgânica e atividade biológica do solo em um agroecossistema em transição agroecológica no Brejo paraibano, e a eficiência destes métodos para a caracterização de solos com melhor qualidade.

\section{METODOLOGIA}

A pesquisa foi desenvolvida em um agroecossistema em processo de transição agroecológica no assentamento Cajazeiras, situado na zona rural do município de Serraria-PB.

Em campo, realizou-se coletas compostas de solos de 0 à $20 \mathrm{~cm}$ em quatro subsistemas (Banana, Horta, Policultivo e Mata secundária. O solo do agroecossistema foi classificado como ARGISSOLO VERMELHO Distrófico com textura Franco-Argilosa, conforme o Sistema Brasileiro de Classificação de Solos - SiBCS (EMBRAPA, 2013).

A análise da MOS e Atividade biológica foi realizada no Laboratório de Solos do Centro de Ciências Humanas, Sociais e Agrárias (CCHSA) localizado na Universidade Federal da Paraíba (UFPB), Campus III, Bananeiras-PB. A MOS foi determinada de acordo com os procedimentos analíticos da Embrapa (2011). A atividade biológica foi realizada utilizando o peróxido de hidrogênio volume 10 e amostras de solo de cada subsistema. Inicialmente foram pesadas com auxílio da balança analítica digital, $10 \mathrm{~g}$ de cada amostra de solo para $20 \mathrm{ml}$ de peróxido de hidrogênio no qual o peróxido reagiu com às membranas dos microrganismos do solo liberando gás carbônico $\left(\mathrm{Co}_{2}\right)$ das amostras (adaptado de BORGES et al., 2013). Avaliou-se visualmente qual amostra efervesceu mais ou menos no tempo estimado de 5 minutos e foram atribuídos níveis relativos em uma escala de 1 (muito baixo) 2 (baixo), 3 (médio), 4 (alto) e 5 (muito alto) (NICHOLLS et al., 2004). Para as análises dos dados, foram utilizados nesse método uma abordagem descritiva das médias dos teores de matéria orgânica e da atividade biológica em quatro tratamentos, duas variáveis e três repetições. 


\section{RESULTADOS E DISCUSSÕES}

Com base nos resultados apresentados na figura 1, observa-se os valores médios dos teores de MOS e atividade biológica dos subsistemas Banana, Horta, Policultivo e na Mata do agroecossistema.

Figura 1: Valores médios para os teores de matéria orgânica e atividade biológica

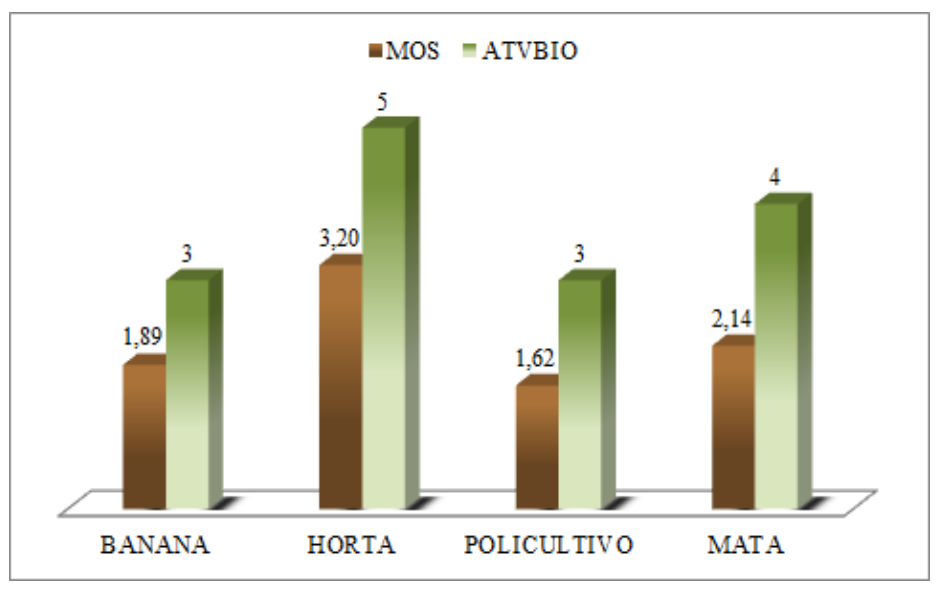

Fonte: Própria (2020).

Para as variáveis de Matéria Orgânica do Solo (MOS) e Atividade Biológica o subsistema que obteve maior índice foi a Horta, no qual é depositado constantemente composto orgânico pelos agricultores devido a sua maior reciclagem de nutrientes e exigência nutricional das hortaliças, se classificando na categoria alta para os teores de MOS e muito alta para categoria de efervescência do peróxido. A atividade biológica, assim como altos teores de MOS, ajudam a determinar a fertilidade do solo, sendo essenciais para o desempenho de funções como a ciclagem de nutrientes, produção de alimentos e estoque de gás carbônico atmosférico (MELO et al., 2019).

O subsistema de Mata obteve os segundos melhores resultados para as duas variáveis analisadas, apresentando classificação média para os teores de MOS e alta efervescência para atividade biológica. A Mata possui vegetação de floresta secundária ombrófila estacional semidecidual, sendo às principais espécies: embaúba (Cecropia), jatobá (Hymenaea courbaril), macaíba (Acrocomia aculeata) e jenipapo (Genipa americana). Considerado um ambiente biodiverso e favorável para boas taxas de ciclagem de nutrientes e diversidade microbiana. Segundo Primavesi \& Primavesi (2018) o maior teor de $\mathrm{CO}_{2}$ pode ser verificado em solos de florestas e de hortas bem adubadas, se regulando, automaticamente no solo. Já para conservação dos solos tropicais, a inserção de material orgânico deve ser contínua tendo em vista a rápida degradação dos compostos orgânicos e minerais presentes no material de origem (MELO et al., 2019).

Os subsistemas de cultivo de Banana e Policultivo lograram teores médios de MOS e de atividade biológica, na qual é cultivado a cultura da banana (Musa sp.) e no Policultivo são cultivados às espécies de urucun (Bixa orellana), feijões (Phaseolus vulgaris, Vigna unguiculata e Cajanus 
cajan), milho (Zea mays) e mandioca (Manihot esculenta Crantz), a família agricultora sempre deixa os resíduos vegetais para cobrir e nutrir o solo. Nesse sentido, Machado e Machado Filho (2017) citam que a matéria orgânica proporciona benefícios positivos em funções no solo, desde absorção e retenção de água até armazenar carbono, macro e microelementos no solo.

Em relação a Atividade biológica, Nicholls et al., (2004) afirma que a determinação da atividade microbiológica e do carbono orgânico do solo pelo peróxido possui viabilidade de uso, pois, os teores não diferem consideravelmente se comparados ao método padrão adotado. Borges et al., (2013) apresentam o uso do peróxido de hidrogênio como uma alternativa viável, simples e ecológica para determinar a atividade microbiológica e carbono orgânico.

Essa quantidade produzida de $\mathrm{CO} 2$ depende dos organismos decompositores da matéria orgânica e das condições de solo. O que, de acordo com Primavesi \& Primavesi (2018), o manejo agroecológico do solo significa manejar recursos naturais respeitando a teia da vida relativa à atividade biológica como processo chave, trabalhando de acordo com a reciclagem de nutrientes e características locais do ambiente.

\section{CONCLUSÕES}

Os solos do agroecossistema apontaram de médio a altos teores de Matéria Orgânica do Solo e Atividade Biológica nos diferentes subsistemas. O subsistema Horta logrou classificação alta para o teor de MOS e maior efervescência para a Atividade Biológica do Solo.

Os demais subsistemas alcançaram classificação média para o teor de MOS e boa taxa de efervescência com o peróxido para atividade biológica. Os solos do agroecossistema possuem boa qualidade, apontando importante condição para o fortalecimento da segurança alimentar e nutricional, e avanço na transição agroecológica.

\section{PRINCIPAIS REFERÊNCIAS}

BALOTA, E. L.: Manejo e qualidade biológica do solo. 1. ed. Londrina: Midiograf, 280 p. 2018.

BORGES, P. H. C.; PASSOS, F. R.; PINTO. M. E. de C.; ALMEIDA, W. L.; MENDES, F. Q.; CARVAlHO, A. M. X. Peróxido de Hidrogênio na Determinação dos Teores de Carbono Orgânico do Solo - uma Alternativa Simples e de Menor Impacto Ambiental. Cadernos de Agroecologia, v. 8, p. 2 - 8. 2013.

CARDOSO, I. M.; FÁVERO, C. Solos e agroecologia. (Coleção transição agroecológica). v. 4. Editores técnicos - Brasília, DF: Embrapa, 373 p. 2018.

DORAN, J. W. Soil health and sustainability. Advances in Agron., v. 56, p. 1-54, 1996. 
EMBRAPA. Sistema Brasileiro de Classificação de Solos. 2. ed. Rio de Janeiro: Embrapa Solos, 306p. 2013.

EMBRAPA. Manual de Métodos de Análise de Solo. 2. ed. Rio de Janeiro: Embrapa Solos. 2011.

FARINE, E. L.; MOREIRA, D. A.; NARDO, A. E.; CAMARGO, I. S. P.; JORDÃO, L. T.; GERMANO, M. G.; KLEINERT, J. J.; OLIVEIRA JUNIOR, A. Comparação de dois métodos para determinação do teor de carbono orgânico do solo. Vi Jornada Acadêmica da Embrapa Soja, Londrina, v. 3, n. 6, p.1-3, 2011.

MACHADO, L. C. P.; MACHADO FILHO, L. C. P.. A Dialética da Agroecologia: contribuição para um mundo com alimentos sem veneno. São Paulo: Expressão Popular, 360 p. 2017.

MELO, D. M. A.; REIS, E. F.; COARACY, T. N.; SILVA, W. A. O.; ARAÚJO, A. E. Cromatografia de Pfeiffer como indicadora agroecológica da qualidade do solo em agroecossistemas. Revista Craibeiras de Agroecologia, v. 4, n. 1, 2019.

MIELNICZUK, J. Matéria Orgânica e a Sustentabilidade de Sistemas Agrícolas. In: SANTOS, G.A.;

NICHOLLS, C. I.; ALTIERI, M. A.; DEZANET, A.; LANA, M.; FEISTAUER, D.; OURIQUES, M. A rapid farmer-friendly agroecological method to estimate soil quality and crop health in vineyard systems. Biodynamics, Pottstow, n. 250, p. 33-40, 2004. 